O histórico da EHP presta-se para mostrar-lhes que apenas com tenacidade e paciência a ciência consegue explicar os fenômenos mais incríveis que observamos na prática clínica diária.

\section{Referências bibliográficas}

1. Dufour H; Fredet P. La stenose hypertrophique du pylore chez le nourrison et son traitement chirurgical. Revue de Chirurgie 1908; 37:208.

2. Spitz L, Zail SS. Serum gastrin levels in congenital hypertrophic stenosis. J Pediatr Surg 1976; 11:33.

3. Janik JS, et al. The role of gastrin in congenital hypertrophic pyloric stenosis. J Pediatr Surg 1978; 13:151.

4. Belding HH, Kernohan JW. A morphologic study of the myenteric plexus and musculature of the pylorus. Surg Gynecol Obstet 1953; 97:322
5. Friensen SR, Boley J, Miller DR. The myenteric plexus of the pylorus: its early normal development and its changes in hypertrophic pyloric stenosis. Surgery 1956; 39:21.

6. Spitz L, Kaufmann JCE. The neuropathological changes in congenital hypertrophic pyloric stenosis. South African J Surg $1975 ; 13: 239$.

7. Kobayashi H, O’Brian DS, Puri P. Selective reduction in intramuscular nerve supporting cells in infantile hypertrophic pyloric stenosis. J Pediatr Surg 1994; 29:651.

8. Furchgott RF, Zawadzki JV. The obligatory role of endothelial cells in the relaxation of arterial smooth muscle by acetylcholine. Nature 1980; 228:373.

9. Ignarro LJ, et al. Activation of purified soluble guanylate cyclase by endothelium derived relaxing factor from intrapulmonary bradykinin and arachidonic acid. J Pharmacol Exp Ther 1986; 237:893.

10. Voelker CA, et al. Perinatal nitric oxide synthase inhibition retards neonatal growth by inducing hypertrophic pyloric stenosis in rats. Pediatric Research 1995; 38:768.

\title{
Um "experimento natural" de mortalidade de recém-nascidos de muito baixo peso
}

\author{
A "natural experiment" regarding the mortality of very low birth weight infants
}

\author{
Renato Machado Fiori*
}

O estudo publicado nesta edição do Jornal de Pediatria por Alicia Matijasevich et al. sob o título “Atención de Salud en Niños de Muy Bajo Peso al Nascer en Montevideo" aborda a questão da qualidade do tratamento intensivo neonatal público e privado em Montevidéu.

A comparação da qualidade da assistência perinatal em diferentes hospitais através da análise de resultados é praticamente inviabilizada pelas grandes diferenças das populações estudadas. Condições prévias de saúde materna, nível socioeconômico, graus de complexidade assistencial dos hospitais e tipos de pacientes referidos introduzem vieses que as mais complexas análises estatísticas quase nunca conseguem superar. Entretanto, utilizando-se de uma circunstância especial de possibilidade de transferência de crianças nascidas em hospitais públicos para hospitais privados em Montevidéu, o autor conseguiu mimetizar um modelo experimental, comparando dois grupos de recém-nascidos de muito baixo peso, cujas mães provinham do mesmo sistema assistencial, os quais foram alocados, supostamente ao acaso, para receber tratamento

\footnotetext{
* Prof. Titular de Pediatria da FAMED da PUCRS. Chefe do Serviço de Neonatologia do Hospital São Lucas da PUCRS.
}

intensivo ou num hospital público ou num hospital privado. De alguma forma, este modelo lembra o célebre "experimento natural" de John Snow, no século XIX, em Londres, o qual, aproveitando-se do fato de que uma companhia fornecedora de água, ao contrário de outra, passara a retirar água do Rio Tâmisa antes que este atravessasse a cidade, comparou a prevalência de cólera nas populações servidas pelas duas companhias, concluindo que a epidemia devia-se à contaminação do rio ao atravessar a cidade ${ }^{1-2}$

Deve-se salientar que esta possibilidade de transferência de recém-nascidos do sistema público de saúde para o sistema privado oferecida pela cidade de Montevidéu é pouco comum na América Latina.

Os recém-nascidos enviados aos hospitais privados tinham características que sugeriam maior risco de morte. Eram mais imaturos, receberam menos corticóide pré-natal e tiveram Apgar mais baixo aos 5 minutos de vida; necessitaram na sala de partos mais vezes oxigênio, ventilação com máscara e intubação endotraqueal. O autor aparentemente não conseguiu coletar dados para estabelecer um índice prognóstico, como o CRIB, o qual ajudaria a definir melhor a perspectiva de desfecho de cada um dos grupos. 
A mortalidade não foi diferente nos recém-nascidos entre 1.000 e 1.499 gramas nos grupos internados em hospitais privados e públicos. Entretanto, foi encontrada uma diferença estatisticamente significativa na mortalidade dos recém-nascidos de menos de 1.000 gramas (11 óbitos de um total de 23 recém-nascidos nos hospitais privados e 15 óbitos de um total de 18 nos hospitais públicos), levando $o$ autor a sugerir uma diferença na qualidade da assistência dos dois sistemas, embora o mesmo reconheça a falta de poder do estudo ocasionada pela pequena quantidade de casos analisados.

A diferença encontrada apenas na faixa de menos de 1.000 gramas é esperada. É justamente neste grupo de recém-nascidos de altíssimo risco que a diferença na qualidade do tratamento intensivo se traduz por resultados diferentes. Em grupos de recém-nascidos de maior peso, que requerem menos vezes controles e tratamentos sofisticados, as variações na qualidade da assistência mostram diferenças de resultados menos perceptíveis. A mortalidade dos recém-nascidos de menos de 1.000 gramas reflete a qualidade do tratamento intensivo numa UTI Neonatal tanto quanto o índice de baixo peso ao nascer em uma maternidade reflete a qualidade da população que a freqüenta.

Nos países desenvolvidos a mortalidade destes recémnascidos tem caído dramaticamente. Um levantamento feito em unidades de tratamento intensivo neonatal de 14 universidades norte-americanas, nos anos de 1995 e 1996, mostrou uma sobrevivência de $84 \%$ dos recém-nascidos com peso ao nascer entre 500 e 1.500 gramas e $54 \%$ dos com peso entre 501 e 750 gramas $^{3}$. Recém-nascidos prétermo na faixa entre 400 e 500 gramas e idade gestacional de 23 a 25 semanas passaram a sobreviver em percentual significativo em vários centros ${ }^{4}$.

A mortalidade das crianças de menos de 1.000 gramas ao nascer corresponde em geral a quase metade e, em alguns centros, a mais da metade da mortalidade neonatal. Portanto, a redução da mortalidade infantil a níveis próximos aos dos países desenvolvidos passa também, obrigatoriamente, por bons resultados do tratamento intensivo deste grupo de recém-nascidos de extremo baixo-peso e, por consequiência, por boas unidades de tratamento intensivo neonatais públicas, onde é tratada a grande maioria destas crianças, pelo menos as nascidas nas cidades mais populosas e nas áreas mais desenvolvidas da América Latina em que este nível de tratamento é disponível.

Bons resultados quanto à sobrevivência de recém-nascidos de extremo baixo peso somente são obtidos com um conjunto complexo de condições que começam por área física e equipamentos para monitoração e tratamento apropriados, por laboratório e equipamentos para diagnóstico por imagem modernos e terminam, acima de tudo, por neonatolgistas experientes e enfermeiras capazes, em número suficiente, treinados em tratamento intensivo neonatal. Este conjunto tem inegavelmente um custo elevado de montagem e manutenção que se justifica em locais que já superaram os desafios da assistência básica de saúde das suas crianças.

O autor não teve por objetivo (ou simplesmente não relata neste artigo) uma avaliação das possíveis causas da diferença de mortalidade encontrada, que certamente se localiza em uma ou mais das condições acima mencionadas.

A experiência e a visão do autor deste artigo permitiram a realização deste "experimento" que chama a atenção para a qualidade do tratamento intensivo neonatal e suas consequiências em hospitais públicos, um tema de saúde pública de alta relevância para toda a América Latina.

\section{Referências bibliográficas}

1. Hardy A. Medical History 1911(Suppl No 11), 76-93.

2. Snow J. On the mode of communication of cholera. 1855.

3. Lemons JA, Bauer CR, Oh W, Korones SB, Papile LA, Stoll BJ, et al. Very low birth weight outcomes of the National Institute of Child Health and Human Development Neonatal Research Network, January 95 through December 96. Pediatrics 2001:107: E1.

4. Lorenz JM. Survival of the extremely preterm infant in North America in the 1990s. Clinics in Perinatology 2000;27:255-62. 